\title{
Frictional performance of silicon carbide under different lubrication conditions
}

\author{
Xingyu ZHAO, Ying LIU*, Qingfeng WEN, Yuming WANG \\ State Key Laboratory of Tribology, Tsinghua University, Beijing 100084, China \\ Received: 26 June 2013 / Revised: 26 November 2013 / Accepted: 03 January 2013 \\ (C) The author(s) 2014. This article is published with open access at Springerlink.com
}

\begin{abstract}
The frictional performance of materials used in face seals is critical to the sealing performance. Silicon carbide is commonly used in hard rings because of its abrasion resistance, corrosion resistance, and thermal shock resistance. In this study, the frictional performance of silicon carbide, including graphite-added silicon carbide, under water and lubrication-absent conditions was studied by using a Falex-1506 tribotester and different working parameters. In addition, the morphology of the worn surfaces was observed using scanning electron microscopy and the damage was characterized to understand the tribological behavior of different silicon carbides. The results suggest that the friction coefficients decrease with increasing pressure under water lubrication conditions because of the water within the holes on the surface of the materials. The percentage of water lubrication increases, whereas the percentage of solid friction decreases when the pressure increases. Under dry contact conditions, the friction coefficients change negligibly with increasing pressure and graphite-added silicon carbide shows better frictional performance.
\end{abstract}

Keywords: Silicon carbide; frictional performance; water, lubrication; wear mechanism

\section{Introduction}

The frictional performance of materials used in mechanical seals is critical to sealing performance [1]. Silicon carbide is commonly used in mechanical face seals because of its abrasion resistance, corrosion resistance, and thermal shock resistance. Moreover, sintered $\mathrm{SiC}$ is porous and the holes in it act as fluid reservoirs, thus maintaining the fluid film. Previous studies showed that the control of porosity results in better frictional performance and thermal shock resistance [2].

In soft and hard pairs of graphite and silicon carbide ( $\mathrm{SiC})$, the soft material is worn more than the hard material when the seals work under high speed or

* Corresponding author: Ying LIU.

E-mail: liuying@mail.tsinghua.edu.cn

A preliminary version of this work was presented at the $3^{\text {rd }}$ International Symposium on Tribology of IFToMM, Luleå, Sweden, 2013. high pressure. To increase the wear resistance of seal faces, hard/hard pairs of silicon carbide-based materials are used. Several researchers observed lower friction coefficients and lower wear rates in sliding surfaces by coating the SiC substrates with diamond-like carbon (DLC) or graphite-like carbon (GLC) on Refs. [3-4].

Pure water is environmentally friendly and inexpensive; hence, pure water hydraulic systems have been applied in industry, e.g., food processing and nuclear engineering. In addition, the frictional or hydrothermal performance of silicon carbide under water lubrication conditions is under increasing scrutiny [5-6].

A small quantity of free graphite exists in graphiteadded sintered silicon carbide. Free graphite has selflubrication and anti-wear properties [7]. Researchers have been trying to improve the frictional performance of silicon carbide by using graphite-like carbon films under dry and water lubrication conditions [8-9]. 
Silicon carbide is commonly used in mechanical seals of reactor coolant pumps. The sealing system works in the presence of water under normal working conditions and may briefly experience dry contact conditions during starting and stopping. Free graphite is added to silicon carbide to improve its frictional performance. This study aims to understand the frictional performance of sintered silicon carbide and graphite-added sintered silicon carbide under water lubrication and dry contact condition.

The load was varied and the tribology experiments were performed on a Falex-1506 tribotester. To understand the tribological performance of different silicon carbides, the morphology of the worn surfaces was observed by scanning electron microscopy (SEM).

\section{Experimental details}

\subsection{Experimental materials}

The materials used in the experiments are sintered silicon carbide, and are currently used or may be used in the future in mechanical seals. Their mechanical and physical properties are listed in Table 1. The materials are WNV2, sintered pressureless-bonded $\mathrm{SiC}$ (PLSiC); CHV1, graphite-added PLSiC; R, sintered reaction-bonded $\mathrm{SiC}(\mathrm{RBSiC})$; and $\mathrm{R} 2$, graphite-added RBSiC.

\subsection{Experimental parameters}

The experiments were performed on a Falex-1506 tribotester. The upper sample is an annular ring with an inner diameter of $25.5 \mathrm{~mm}$ and an outer diameter of $28.5 \mathrm{~mm}$. Underneath the upper sample, the stationary sample is a ring with an inner diameter of $15.8 \mathrm{~mm}$ and an outer diameter of $31.7 \mathrm{~mm}$. The upper ring rotates against the stationary one and the friction torque is measured by a sensor (Fig. 1).

The experiments were performed in room temperature and the operational parameters of the experiments are listed in Table 2.

Eight hard/hard frictional pairs (Table 3) were tested under different loads to investigate the influence of the materials and pressure on friction under dry and water lubrication conditions.
Table 1 Mechanical and physical properties of the materials used in the experiments.

\begin{tabular}{ccccc}
\hline \multicolumn{2}{c}{ Material } & $\begin{array}{c}\text { Density } \\
\left(\mathrm{g} / \mathrm{cm}^{3}\right)\end{array}$ & $\begin{array}{c}\text { Young's } \\
\text { modulus } \\
(\mathrm{GPa})\end{array}$ & $\begin{array}{c}\text { Porosity } \\
(\mathrm{vol} \%)\end{array}$ \\
\hline $\begin{array}{c}\text { Without } \\
\text { graphite }\end{array}$ & WNV2 & 3.06 & 374 & 2.5 \\
\hline $\begin{array}{c}\text { With } \\
\text { graphite }\end{array}$ & CHV1 & 2.96 & 356 & 2.5 \\
\hline
\end{tabular}

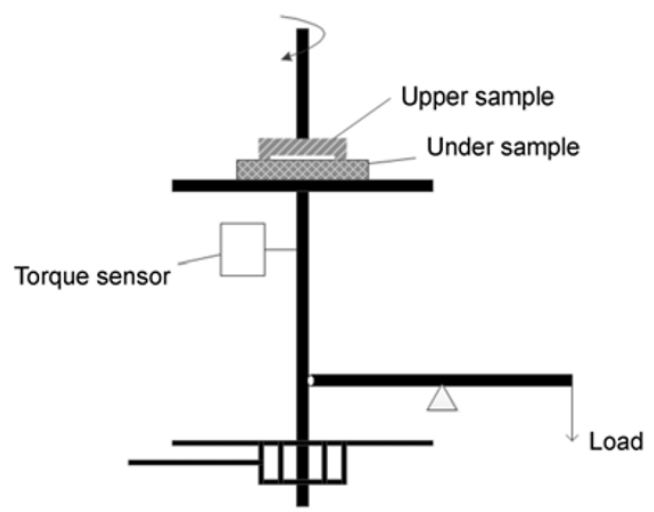

Fig. 1 Schematic of the experimental setup.

Table 2 Experimental parameters.

\begin{tabular}{ccccc}
\hline $\begin{array}{c}\text { Lubrication } \\
\text { conditions }\end{array}$ & $\begin{array}{c}\text { Loading } \\
\text { range }(\mathrm{MPa})\end{array}$ & $\begin{array}{c}\text { Velocity } \\
\text { range }(\mathrm{m} / \mathrm{s})\end{array}$ & $\begin{array}{c}\mathrm{PV} \\
(\mathrm{MPa} \cdot \mathrm{m} / \mathrm{s})\end{array}$ & $\begin{array}{c}\text { Duration } \\
(\mathrm{min})\end{array}$ \\
\hline $\begin{array}{c}\text { Deionized } \\
\text { water }\end{array}$ & $0.70-2.80$ & 5.074 & $3.55-14.21$ & 10 \\
$\begin{array}{c}\text { Dry contact } \\
\text { Dry }\end{array}$ & $0.31-0.69$ & 0.665 & $0.21-0.46$ & 10 \\
\hline
\end{tabular}

Table 3 Frictional pairs.

\begin{tabular}{ccc}
\hline Pair conditions & No. & Friction pairs \\
\hline \multirow{3}{*}{ Self-mated pair } & 1 & WNV2/WNV2 \\
& 2 & CHV1/CHV1 \\
& 3 & R/R \\
& 4 & R2/R2 \\
\hline \multirow{3}{*}{ Nonself-mated pair } & 5 & WNV2/CHV1 \\
& 6 & WNV2/R2 \\
& 7 & CHV1/R2 \\
& 8 & R/R2 \\
\hline
\end{tabular}

\section{Results and discussion}

\subsection{Water lubrication conditions}

Two types of hard/hard pairs are specified. The first is the self-mated pair, which means sliding pairs of materials with the same hardness, such as WNV2/WNV2 
(No. 1, Table 3). The other is the nonself-mated pair, such as WNV2/CHV1 (No.1, Table 3). The friction coefficients of the self-mated pairs under different contact pressures (0.70-2.80 MPa) and average circumferential speed of $5.074 \mathrm{~m} / \mathrm{s}$ are shown in Fig. 2. Sliding scratches were observed on the surface (Fig. 3(b)) and the friction coefficient range was $0.05-0.18$. It was confirmed that these pairs are sliding under mixed lubrication conditions [10]. From Fig. 2, it is seen that the friction coefficients of the self-mated pairs decrease with increasing pressure. The same trends are obtained when the sliding pairs are replaced by nonself-mated pairs (Fig. 4). The small holes on the surface of silicon carbide (Fig. 5(b)) become larger and contain more fluid under high pressure because of the elastic deformation or wear. As a result, when the pressure increases the percentage of water lubrication increases, whereas the percentage of solid friction decreases. The friction coefficients consequently decrease. This is shown by comparing the trends of the friction coefficients under dry contact (Figs. 6 and 7) and water lubrication conditions.

As can be seen from Figs. 2 and 4, hard/hard pairs with CHV1 or R2 have better friction performance under water lubrication than pairs without them, which is attributed to the added graphite. However, this behavior is more pronounced in CHV1 than R2. From the SEM micrographs of the wear tracks (Fig. 8), it can be seen that the wear mode is abrasion for CHV1 and adhesion for R2, which may be related to the abovementioned phenomena. However, whether transfer of material occurs or not needs to be further studied.

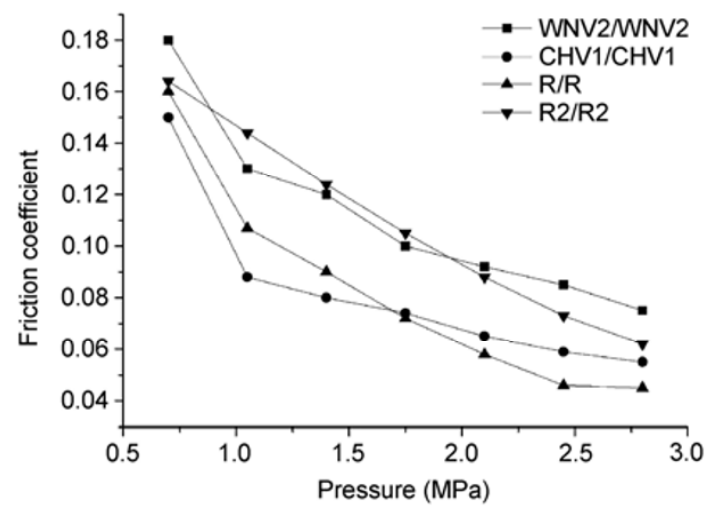

Fig. 2 Friction coefficient variation of self-mated pairs under water lubrication and different pressure conditions.

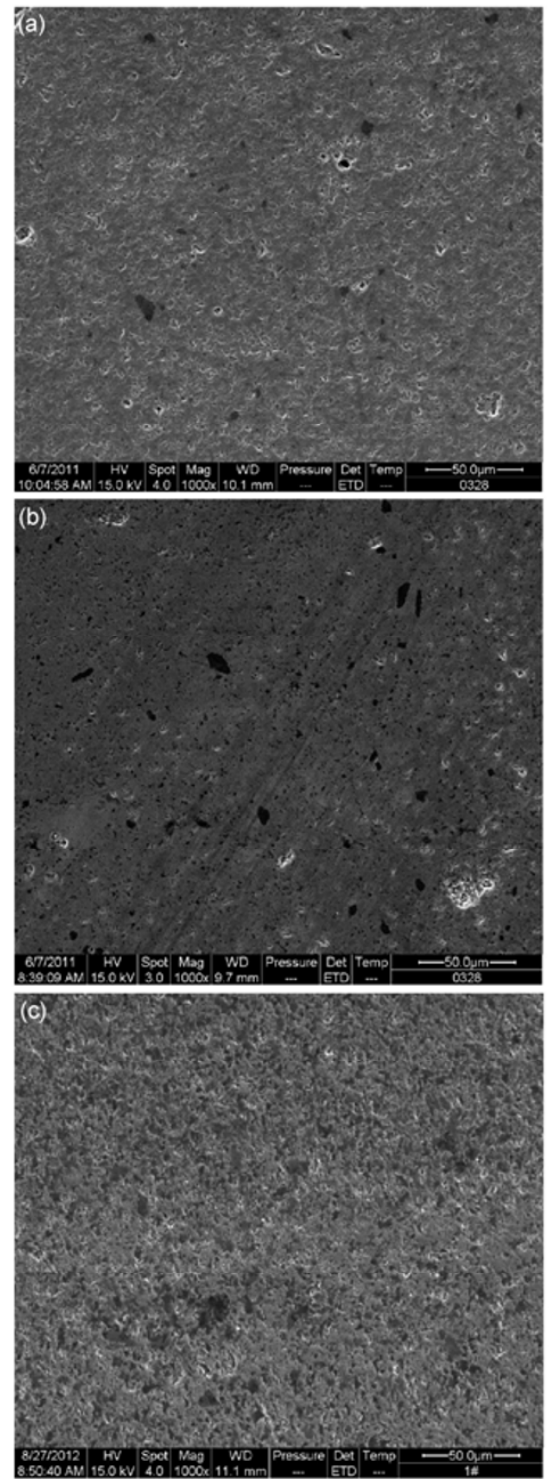

Fig. 3 SEM micrographs of WNV2 under dry contact and water lubrication conditions for WNV2/WNV2 pair. (a) Before test; (b) after test under water lubrication $(2.80 \mathrm{MPa})$; (c ) after test under dry contact (0.69 MPa).

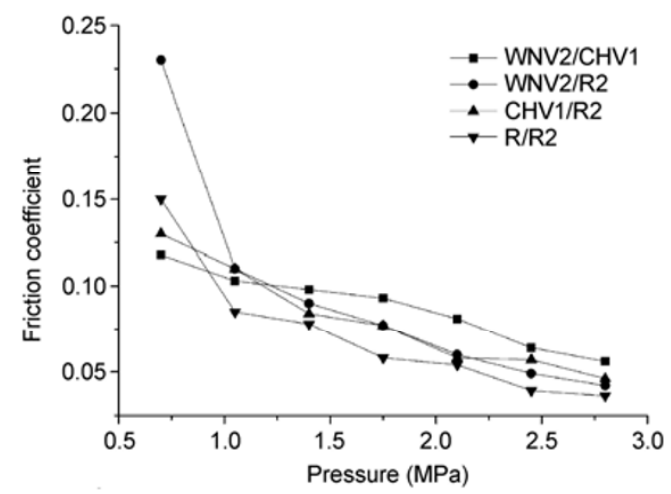

Fig. 4 Friction coefficient variation of nonself-mated pairs under water lubrication and different pressure conditions. 

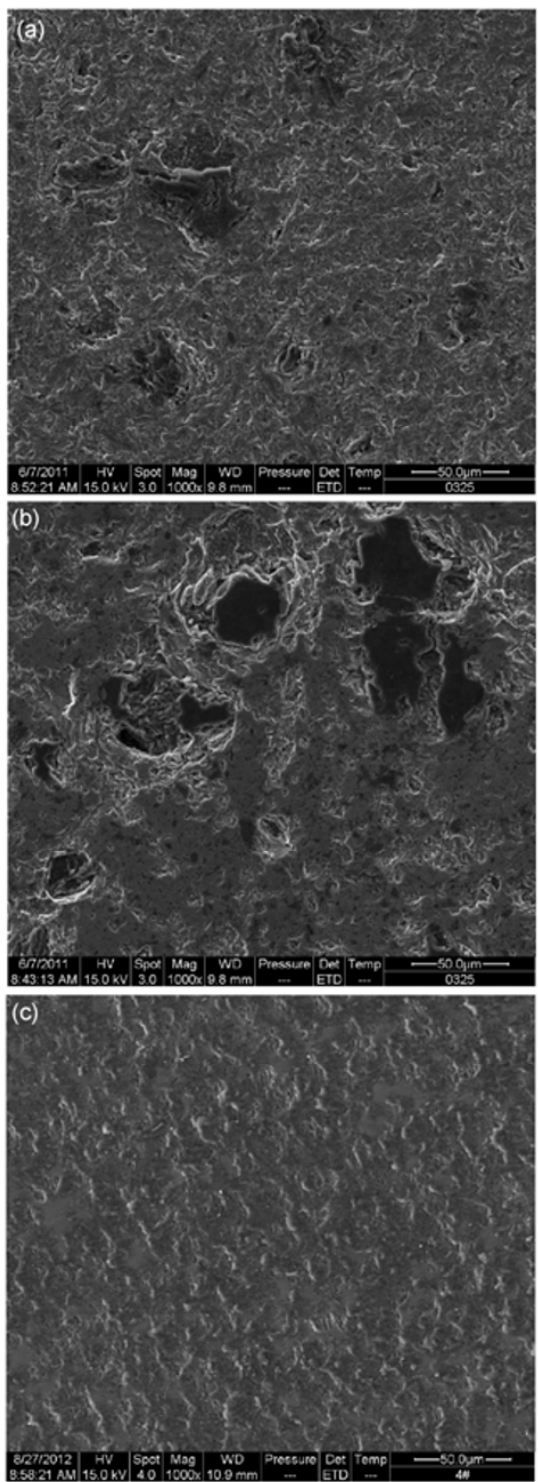

Fig. 5 SEM micrographs of CHV1 under dry contact and water lubrication conditions for the CHV1/CHV1 pair. (a) before test; (b) after test under water lubrication $(2.8 \mathrm{MPa})$; (c) after test under dry contact $(0.69 \mathrm{MPa})$.

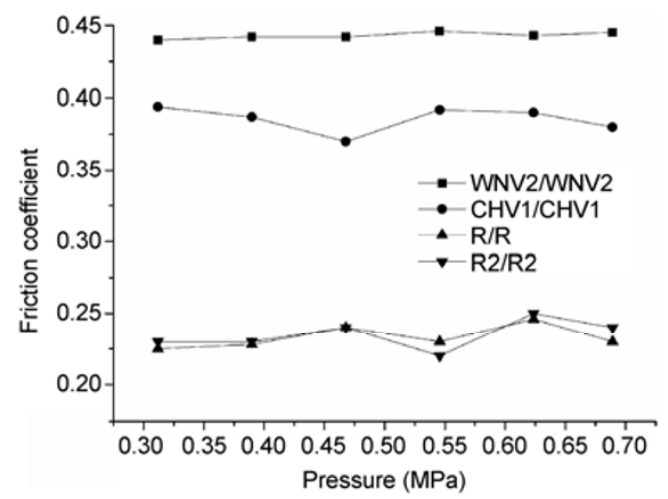

Fig. 6 Friction coefficient variation of self-mated pairs under dry contact and different pressure conditions.

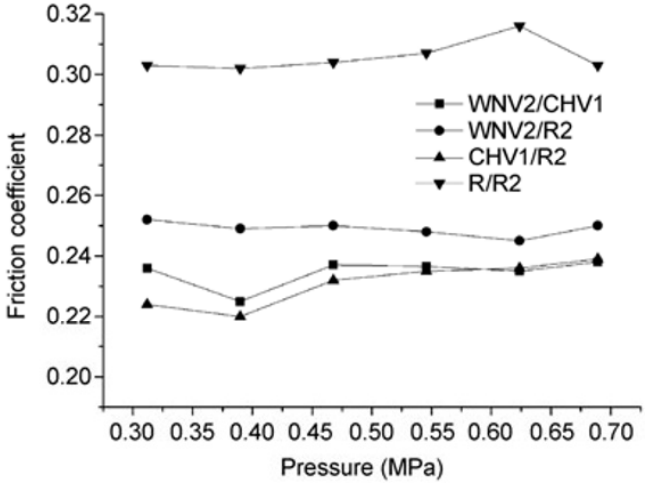

Fig. 7 Friction coefficient variation of nonself-mated pairs under dry contact and different pressure conditions.

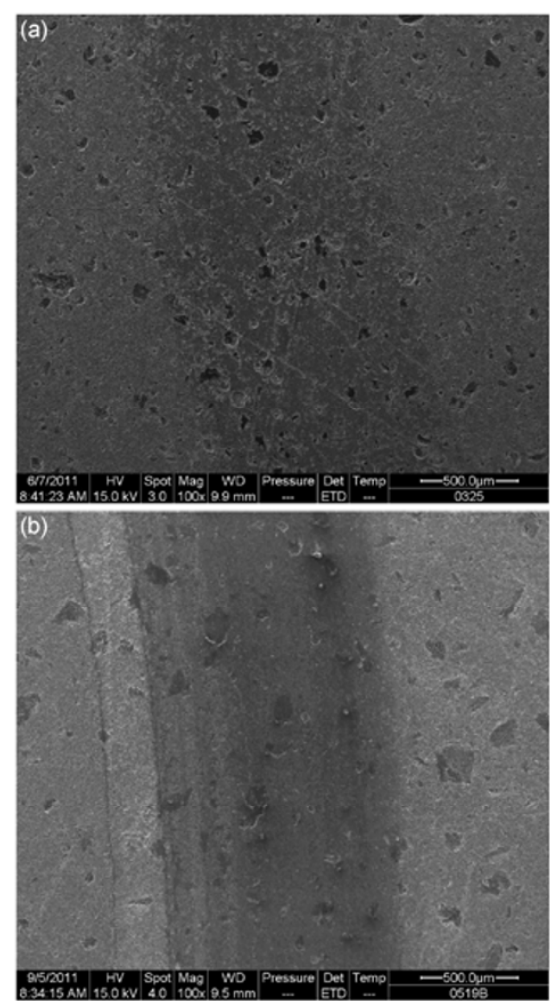

Fig. 8 SEM micrographs of wear tracks in self-mated pairs under water lubrication conditions. (a) CHV1 and (b) R2.

\subsection{Dry contact conditions}

The friction coefficients of self-mated pairs under different contact pressures are shown in Fig. 6. It can be seen that the friction coefficients vary little as the contact pressure increases. This also applies to the nonself-mated pairs.

Self-mated pairs of graphite-added sintered silicon carbide have better frictional performance under dry contact conditions because free graphite in graphiteadded silicon carbide has self-lubricating properties. 
The bulk wear loss is shown in Fig. 9. The bulk wear loss of pairs with RBSiC is greater than without it. Considering the low friction (less than 0.25) and the bulk wear loss, the WNV2/CHV1 and CHV1/R2 pairs show better performance.

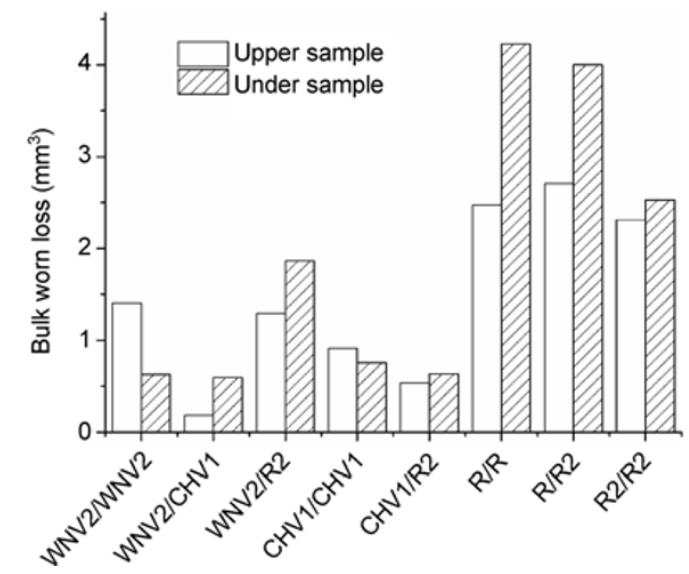

Fig. 9 Bulk wear loss of silicon carbide (30 min).

\subsection{Wear mechanism}

Using WNV2/WNV2 and CHV1/CHV1, as an example, the wear mechanism of silicon carbide under dry contact and water lubrication conditions is shown in Figs. 3(a)-3(b) and 5(a)-5(b), respectively. Under water lubrication conditions, while the contact pressure is low (less than 1.1 MPa), the friction coefficient is high. As the load increases and water lubrication becomes dominant, the friction coefficient decreases.

Under dry contact conditions, the surface is severely worn (Figs. 3(c) and 5(c)). As the range of contact pressure is not sufficiently broad, the contact area of the asperity changes slightly and thus, the friction coefficient remains the same.

\section{Conclusions and recommendations}

The frictional performance under dry contact and water lubrication conditions of eight hard/hard pairs of four sintered silicon carbide-based materials (WNV2, CHV1, R, and R2) was tested by using a Falex-1506 tribotester. Under water lubrication conditions and the working load and velocity range, the pairs are sliding in mixed lubrication conditions with friction coefficients from 0.02 to 0.24 . The friction coefficients of different pairs of sintered silicon carbide in mechanical seals decrease as the load increases because of water in the small holes on their surface. The percentage of water lubrication increases, whereas the percentage of solid friction decreases with increasing pressure. Moreover, graphite-added pressureless sintered silicon carbide (CHV1) showed improved tribological performance compared with graphite-added reaction-bonded silicon carbide (R2); the wear mode was abrasion for CHV1 and adhesion for R2, which may be the reason for it.

Under dry contact conditions, the friction coefficient changes negligibly with increasing load. Graphiteadded sintered silicon carbide has better frictional performance in the examined load and velocity range, presumably, because of the self-lubricating properties of free graphite.

\section{Acknowledgements}

This work was supported by the National Basic Rese arch Program of China (973) (Grant No. 2009CB724304), the National Natural Science Foundation of China (Grant No. 51275268), and State Key Laboratory of Tribology (Grant No. SKLT11C4). The authors would like to thank Enago (www.enago.cn) for the English language review.

Open Access: This article is distributed under the terms of the Creative Commons Attribution License which permits any use, distribution, and reproduction in any medium, provided the original author(s) and source are credited.

\section{References}

[1] Lebeck A O. Principles and Design of Mechanical Face Seals. New York: Wiley, 1991.

[2] Divakar R. Sintered silicon carbides with controlled porosity for mechanical face seal applications. Lubr Eng 50(1): 75-80 (1994)

[3] Liu X, Wang L, Lu Z, Xue Q J. Vacuum tribological performance of DLC-based solid-liquid lubricating coatings: Influence of sliding mating materials. Wear 292: 124-134 (2012)

[4] Wang Y, Wang L, Xue Q. Improvement in the tribological performances of $\mathrm{Si}_{3} \mathrm{~N}_{4}, \mathrm{SiC}$ and $\mathrm{WC}$ by graphite-like carbon films under dry and water-lubricated sliding conditions. Surf Coat Tech 205(8-9): 2770-2777 (2011) 
[5] Matsuda M, Kato K, Hashimoto A. Friction and wear properties of silicon carbide in water from different sources. Triboly Lett 43(1): 33-41 (2011)

[6] Presser V, Krummhauer O, Nickel K G, Kailer A, Berthold C, Raisch C. Tribological and hydrothermal behaviour of silicon carbide under water lubrication. Wear 266(7-8): 771-781 (2009)

[7] Gu Y Q. Practical Technology of Mechanical Seals. Beijing: Machine Industry Press, 2001.

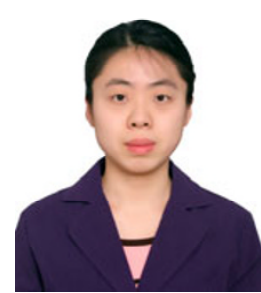

Xingyu ZHAO. She received her Bachelor degree in Mechanical Engineering in 2011 from Tsinghua University, Beijing, China. Now,

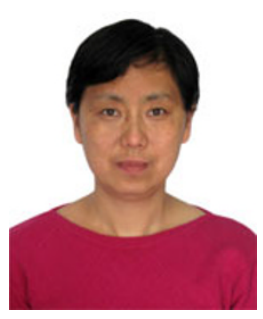

Ying LIU. She received her Doctor's degree of Engineering in 2003 from Tsinghua University. Now she is an associate professor of Department
[8] Jones G A. On the tribological behavior of mechanical seal face materials in dry line contact Part I. mechanical carbon. Wear 256: 415-432 (2004)

[9] Jones G A. On the tribological behavior of mechanical seal face materials in dry line contact Part II. bulk ceramics, diamond and diamond-like carbon films. Wear 256: 433-455 (2004)

[10] Wen S Z, Huang P. Principles of Tribology. Beijing: Tsinghua University Press, 2008

she is a master student in Department of Mechanical Engineering at the same university. Her research interest is in mechanical seals.

of Mechanical Engineering in Tsinghua University. Her academic interest is in Machine Design, tribology and Mechanical seal. 